\title{
Optimization of Warm Mix Asphalts Using Different Blends of Binders and Synthetic Paraffin Wax Contents
}

\author{
Hugo M.R.D. Silva ${ }^{a}$, Joel R.M Oliveira ${ }^{a}$, Joana Peralta ${ }^{a}$, Salah E. Zoorob ${ }^{b}$ \\ ${ }^{a}$ Department of Civil Engineering, University of Minho, 4800-058 Guimaraes, Portugal \\ ${ }^{\mathrm{b}}$ CSIR Built Environment, Pretoria, South Africa
}

\begin{abstract}
In road construction, several processes and products are now available to produce environmentally friendlier warm mix asphalts, including the use of synthetic paraffin wax additives. These additives facilitate the production of energy efficient asphalt mixtures at reduced manufacturing and construction temperatures. However, their sustainability during the road life cycle can only be obtained by optimizing the mixture's performance. Thus, the objective of this work was to assess the properties of different blends of base bitumens (softer to harder ones) containing a range of synthetic wax contents, as well as the performance of the corresponding warm mix asphalts, that could ultimately lead to more sustainable mixtures. It was concluded that different blends should be selected to maximize the temperature reduction, the fatigue or the rut resistance, without compromising the other properties of the mixture.
\end{abstract}

\section{Keywords}

Warm Mix Asphalt; Synthetic Paraffin Wax Additive; Bitumen Modification; Binder Properties; Production Temperature; Mixture Performance; Water Sensitivity; Rut Resistance; Stiffness Modulus; Fatigue Resistance

\section{Introduction}

Currently, one of the most important challenges facing our society is the efficient and economic use of energy (namely by reducing the consumption of fuel), with the corresponding reduction in the emission of greenhouse gases. In response, new energy efficient technologies have been 
developed targeting the production and construction phases of asphalt mixes for road construction. Such technologies, which are being increasingly adopted and applied by road constructors, primarily focus on improving energy efficiency by reducing the temperature of production and application on site of the asphalt mixtures. Of particular interest, is the class of products referred to as warm mix asphalts (WMA) which is applicable to all types of asphalt mixtures applied in different thicknesses and in roads with different traffic levels.

In this study, the potential of one WMA technique is analysed, comprising the modification of the binder via the use of a synthetic wax additive. The wax reduces the binder viscosity and ensures adequate conditions of mixing and compaction at temperatures slightly above $100{ }^{\circ} \mathrm{C}$. With the objective of optimizing this WMA technology for each specific case of application in road pavements (e.g. cold or hot climatic conditions, green production concerns), several blends of base bitumens and synthetic wax contents were prepared in order to obtain WMA modified binders comparable to bitumen grades used in conventional hot mix asphalts (HMA).

Initially, the properties of the HMA and WMA binders (e.g., penetration, softening point, rotational and dynamic viscosity) were assessed in order to select the optimum amount of additive and the permissible practical range for reduction of mixing temperature. Subsequently, the volumetric characterisation of the WMA mixtures produced at different temperatures, obtained after carrying out compactability tests, confirmed the feasibility of temperature reduction between the HMAs and WMAs. Finally, key engineering properties (water sensitivity, stiffness modulus, resistance to fatigue and permanent deformation) of the WMA mixtures produced using the range of aforementioned binders were assessed in order to determine relative levels of performance in comparison with the corresponding HMA mixtures.

\section{Literature Review on WMA}

A number of new processes and products that have the capability of reducing the temperature at which Hot Mix Asphalts (HMA) are mixed and compacted, apparently without compromising 
the performance of the pavement, have become available. Several methods are used to classify these technologies, for example the technologies may be classified by the degree of temperature reduction. As can be observed in Figure 1, WMA are separated from Half WMA by the resulting mix temperature [1]. These new products can reduce production temperatures by as much as $28^{\circ} \mathrm{C}\left(50^{\circ} \mathrm{F}\right)[2]$.

Another way to classify the WMA technologies is by those that use water and those that use some other form of organic additive or wax to effect the temperature reduction. These methods are based on process engineering, aerogenous agents or special bitumens and additives [3]. Thus, several WMA techniques are available and have been studied by several authors, namely; the double-coating or 2-phase mixing method [4]; the application of the double-barrel green process [5], with reductions of 10 to $30^{\circ} \mathrm{C}$; the half-warm mix asphalt technologies that use water or vapour, produced at $90-100^{\circ} \mathrm{C}$ with foamed bitumens $[6,7]$ or at $70-115^{\circ} \mathrm{C}$ with emulsions [8]. One commercial product "Evotherm ${ }^{\circledR}$ " uses an emulsion which is produced using a chemical package designed to enhance coating, adhesion, and workability, in which the majority of the water flashes off as steam when the emulsion is mixed with the aggregates [9]. Other WMA techniques are carried out by modifying the binder or mixture, namely by using aerogenous agents that are based on chemically bound water that is released during asphalt mixing due to the addition of zeolites (reductions of $30^{\circ} \mathrm{C}$ ) [10], and by using organic additives, such as Fischer-Tropsch synthetic waxes that incorporates a low melting point organic additive that chemically changes the temperature-viscosity curve of the binder [11-13] or low molecular weight ester compounds, or additives containing surface active agents that improve the asphalt workability within the production temperature range by up to 30 to $40^{\circ} \mathrm{C}$ during mixing [14].

Lower plant mixing temperatures mean fuel cost savings to the contractor and trials have shown that lower plant temperatures can lead to a significant reduction in fuel consumption [15] and emissions that may contribute to health, odour problems, or greenhouse gas emissions [16]. In this context, typical expected reductions are $30-40 \%$ for $\mathrm{CO}_{2}$ and $\mathrm{SO}_{2}, 50 \%$ for volatile organic compounds, $10-30 \%$ for CO, $60-70 \%$ for nitrous oxides, and $20-25 \%$ for dust. Furthermore, 
savings in the amount of fuel consumed in the burner devices for warming the aggregates in an asphalt plant, that can reach 35\%, are an important argument. On the other hand, a lower production temperature allows the compaction of the mixture at a lower temperature on site, without compromising the desired densities of the resulting layers. The reduction in the exposure to fumes by the workers is another important advantage of this type of mix, with reductions of $30-50 \%$ in comparison with conventional mixes [17]. WMAs also allow longer haulage distances, a longer construction season and minimized oxidative hardening, since the mixes are produced closer to the operating temperatures.

Reducing the environmental impacts caused by industrial activities is a basic condition to adapt the new circumstances of development to the present requirements of sustainability. According to Park et al. [18], the emissions resulting from the production of HMA can significantly vary according to the selected materials, equipment or production modes. However, as stated earlier, it is essential that the overall performance of WMA is at least as good as HMA. On a lifecycle basis, if WMA does not perform so well, there will no longer be long term environmental benefits or energy savings. Several investigators have therefore been studying the performance of the WMA additives, binders [19] and mixtures [20, 12, 17, 21], in order to improve their behaviour. Thus, whilst there is a great deal of promise that can be associated with lower temperatures, there are also concerns [22, 2] about some of the field performance characteristics of WMA mixtures.

\section{Binders Characterisation and Selection of Additive Contents}

3.1. Laboratory tests description

\subsubsection{Rheology tests}

In order to determine any changes in the behaviour of the binders due to the addition of the synthetic wax, the base bitumens, the modified binders and the wax additive were tested in a Dynamic Shear Rheometer (DSR) capable of measuring the rheology of these materials (EN 14770 standard). 
Measurement of the rheological properties of the binders was carried out in a stress controlled rotational DSR with parallel plate sample geometries of $40 \mathrm{~mm}$ diameter and $1 \mathrm{~mm}$ gap (with manual gap compensation at each test temperature). The rheometer was set up to test in an oscillatory mode so as to guarantee a dynamic response from the specimen, ensuring that the specimen was tested in the linear region over the temperature $\left(25\right.$ to $\left.170^{\circ} \mathrm{C}\right)$ and frequency ranges selected $(0.1$ to $10 \mathrm{~Hz})$. Thus, preliminary tests were carried out at different temperatures and frequencies in order to determine the stress range within which the binders remain in the linear viscoelastic range (complex modulus must not differ by more than $5 \%$ of their value over the stress range chosen). Based on this preliminary study, the stress values selected to carry out the DSR tests varied between $1000 \mathrm{~Pa}$ at $25^{\circ} \mathrm{C}$ and $3 \mathrm{~Pa}$ at $170{ }^{\circ} \mathrm{C}$.

The DSR frequency sweeps were initiated at the lowest selected temperature, starting from the lowest frequency and proceeding to the highest. After the completion of each test temperature, it was possible to proceed to the next test temperature at a rate not exceeding $5^{\circ} \mathrm{C}$ per minute. During the test, the selected oscillatory shear stress is applied to the specimen and the resulting shear strain is measured.

\subsubsection{Softening point and penetration tests}

In order to classify the binders used in this study, a basic characterisation was performed in accordance with the EN 12591 standard. This included the tests of penetration at $25^{\circ} \mathrm{C}$ (following the EN 1426 standard) and of softening point (also known as Ring \& Ball temperature, R\&B, according to the EN 1427 standard). These tests were also used to compare the basic characteristics of the bitumens used in the HMAs with those of the modified binders used in the WMAs in order to select the optimum additive content.

\subsubsection{Dynamic viscosity tests}


In order to evaluate the properties of the several binders at higher temperatures $\left(100-170^{\circ} \mathrm{C}\right)$ in which the bituminous mixtures are mixed and applied, their dynamic viscosities were assessed using a rotating spindle apparatus (EN 13302 standard). The typical test temperature of a coaxial viscometer using a rotating spindle apparatus ranges from 50 to $250^{\circ} \mathrm{C}$.

During the test, the torque (relative resistance of the spindle to rotation) applied to a spindle rotating in a special sample container enclosing the binder was used as a measure of dynamic viscosity. According to EN 13302, after setting the test temperature and lowering the spindle into the binder, the system temperature should equilibrate after 15 to 30 min (lab practice showed that the usual equilibrium time is $18 \mathrm{~min}$ ). At least three readings were subsequently recorded between the 18th and 21st minute of the test for each evaluated temperature. The dynamic viscosity at each temperature is the arithmetic mean of these three readings.

Figure 2 summarizes the method used to evaluate the dynamic viscosity of the binders at different temperatures, where the shaded area exemplifies the determination of the dynamic viscosity (2.96 Pa.s) at a temperature of $110^{\circ} \mathrm{C}$. The dashed line represents the theoretical evolution of dynamic viscosity if the test temperature had been gradually increased from 110 to $170^{\circ} \mathrm{C}$. It can also be observed that the viscosity reaches an equilibrium value, at every test temperature, just about after 21 min (18 plus $3 \mathrm{~min}$ ), as stated previously. In this investigation, the theoretical evolution of the dynamic viscosity of several binders with test temperature was the final result of the tests carried out to analyse the optimum amount of additive required to facilitate mixing and applying the WMA at lower temperatures.

\subsection{Characterisation of the WMA additive}

Four paving grade bitumens and one additive type were used in this study with the objective of determining the most appropriate binder constitution for the production of a range of Warm Mix Asphalts adapted to Portuguese conditions. 
The four paving grade bitumens used were a B10/20, a B35/50, a B50/70 and a B160/220 pen bitumen (classified according to the EN 12591). For the "modification" of some of these bitumens, a commercial synthetic paraffin wax additive, known as "Sasobit ${ }^{\oplus,}$, was used in controlled amounts in order to determine its influence on the final binder properties. Other technologies could have been used to produce the WMA mixtures, but the lack of experience in Portugal with these technologies and some technical constraints pointed towards this easier solution of using a WMA additive to modify the bitumen, namely by adding a synthetic wax to reduce the viscosity at production temperatures.

Sasobit ${ }^{\circledR}$ is a Fischer-Tropsch (F-T) or synthetic wax that is created during the coal gasification process and has been used as a compaction aid and a temperature reducer. The Sasobit ${ }^{\circledR}$ process incorporates a low melting point organic additive that physico-chemically interacts with the bitumen, modifying the temperature-viscosity curve of the binder [12]. Sasobit ${ }^{\circledR}$ melts at approximately $100{ }^{\circ} \mathrm{C}$ and significantly reduces the viscosity of the base bitumen. It increases the asphalt resistance to deformation throughout the operating temperature range without affecting the low temperature properties of the mixture, which are determined by the characteristics of the base bitumen [23]. Sasobit ${ }^{\circledR}$ is completely soluble in bitumen at temperatures above $115^{\circ} \mathrm{C}$. It forms a homogeneous solution with base bitumen on stirring reducing remarkably its viscosity. This also enables mixing and reducing by $10-30^{\circ} \mathrm{C}$ the handling temperatures of the asphalt [13]. Experimental work carried out by Hurley and Prowell [11], has shown Sasobit ${ }^{\circledR}$ to improve the compactability of asphalt mixtures when analyzed using either a shear gyratory compactor or a vibratory compactor. Statistical analysis indicated an overall reduction in air voids, and improved compaction was noted at temperatures as low as $190^{\circ} \mathrm{F}\left(88^{\circ} \mathrm{C}\right)$. The research report concludes that the addition of Sasobit ${ }^{\circledR}$ did not affect the resilient modulus of an asphalt mix nor did it increase the rutting potential of asphalt mixtures.

\subsection{Properties of the binders}

3.3.1. Selection of the binder types based on the study of rheology 
Initially, the pen grade bitumen to be used in this study was selected as B50/70, which is commonly applied in Portugal. Meanwhile, in order to compare the performance of HMA and WMA mixtures, the initial idea was to reduce as much as possible the variables in the study (namely the optimum additive content and the corresponding reduction of temperature to produce the WMA mixture). Thus, in this early part of the study, the composition of both HMA and WMA mixtures were kept unchanged (type of aggregates and gradation, bitumen type and percentage of bitumen).

Since this is one of the first studies with WMA mixtures in Portugal, namely by using a synthetic wax additive to reduce the viscosity of the base bitumen at production temperatures, it was decided to carry out an advanced characterisation (rheology using a DSR) of the base bitumen (B50/70), the additive and the binder modified with different amounts of additive (2 to 4\%).

The final results of the rheology test with the DSR involved determining the norm of the complex shear modulus ( $\left|G^{*}\right|$ - ratio between peak stress and peak strain) of the binders over a range of test frequencies and test temperatures. In order to ease the analysis of the rheology results, a reference frequency of $1 \mathrm{~Hz}$ (nearly the $10 \mathrm{rad} / \mathrm{s}$ recommended by SHRP [24]) was selected to compare the different materials tested using DSR. Thus, Figure 3 shows the comparison of the complex modulus of the original bitumen B50/70, the modified binders produced with this bitumen (with 2 and 4\% additive) and the pure additive. The results illustrate the rheological changes due to the use of the additive.

The complex shear modulus of the additive is very high ( $1 \mathrm{MPa}$ at $1 \mathrm{~Hz})$ and constant before its congealing temperature $\left(102^{\circ} \mathrm{C}\right)$, behaving essentially as an elastic solid material. Slightly above that temperature the complex modulus decreases very quickly and the synthetic wax becomes a liquid material. The complex modulus of the original bitumen significantly changes for different test temperatures. At $25^{\circ} \mathrm{C}$ the complex modulus of the original bitumen is lower than that of the wax additive. This difference increases for higher operating temperatures (between 50 and $90^{\circ} \mathrm{C}$ ), at which permanent deformation should occur. Above $115^{\circ} \mathrm{C}$ the 
original bitumen has a complex modulus only slightly higher than that of the wax additive, this difference being insufficient to allow a great reduction of the WMAs production temperature.

The rheology of the binder modified with wax additive is based essentially on the behaviour of the original bitumen. Modifying the original bitumen with the synthetic wax mainly increases the complex modulus in direct proportion to the amount of additive used, which is essentially observed at operating temperatures $\left(25\right.$ to $80^{\circ} \mathrm{C}$ and especially for temperatures near the R\&B softening point). The reduction of the complex modulus at application temperatures (above 120 ${ }^{\circ} \mathrm{C}$ ) is a central objective of WMA additives, but only a minor decrease is obtained by comparing bitumens before and after the modification with the synthetic wax. Thus, the highest quantity of additive (4\%) studied should be used in the modified binder in order to ensure a higher decrease of the complex modulus, maximizing the decrease of WMA application temperatures.

After observing that the synthetic wax additive significantly increases the stiffness modulus of the binder for in service temperatures, the rheology study was continued in order to verify if the B50/70 binder modified with $4 \%$ of additive is comparable, in this range of temperatures (25 to $80^{\circ} \mathrm{C}$ ), to a harder pen grade bitumen (commercial B35/50 bitumen was used in this comparison, since it is also greatly used in Portugal). The comparison between the complex moduli of these binders is presented in Figure 4.

The complex modulus results confirm that the modified binders using softer bitumens have similar or even higher modulus than harder original bitumens, being thus possible to obtain a major reduction of the application temperature of the WMA mixtures and upholding operating properties comparable to the HMA mixtures. Soenen et al. [19] reached similar conclusions for several wax modified binders. Based on the previous results, it was decided that a new line of research should also be carried out, consisting in adding synthetic waxes to softer bitumens in order to produce WMA mixtures that should perform as well as HMA mixtures produced with harder bitumens. Thus, the synthetic wax will be used as a hardener additive at in service 
temperatures, and at the same time it will be possible to obtain a higher reduction of the WMA production temperature (i.e. by using softer bitumens with lower viscosities).

This new line of research was applied in softer commercial bitumens (i.e. by adding synthetic wax to B160/220 bitumen in order to obtain a binder that will be compared with neat B50/70 bitumen) and in harder ones (i.e. by adding synthetic wax to B35/50 bitumen in order to obtain a binder that will be compared with neat B10/20 bitumen). In summary, three comparative studies were carried out between conventional HMA mixtures and WMA mixtures using synthetic wax additive as modifier. Table 1 presents those studies, as well as the classification used for each one of the six mixtures evaluated during the subsequent parts of the work.

The objective of studying these different alternatives is to evaluate the main advantages and disadvantages of several blends of bitumen and synthetic wax (e.g. reduction of the production temperature, resistance to fatigue and permanent deformation, amongst others) in order to select the best combination for each singular case of application of these WMA mixtures (e.g. cold or hot climatic conditions, green production concerns).

In the following part of the investigation, the optimum additive content of every studied WMA mixture was selected in order to guarantee that the basic characteristics of the modified binders are similar to the ones of the corresponding neat bitumen used in the HMA mixture (by comparing the results of the penetration and softening point tests). Subsequently, the reduction in the production temperatures of the WMA mixtures were selected by analysing the results of dynamic viscosity tests.

3.3.2. General properties and selection of additive contents

Several samples of modified binders were prepared in the laboratory for a thorough characterization (penetration and softening point tests). These samples comprised the addition of three percentages of synthetic wax additive to each penetration grade bitumen used in the 
three comparative studies (A - B50/70; B - B160/220; C - B35/50). Based on the recommendations of the additive producers and on the previous results of rheology, synthetic wax contents of 2, 3 and $4 \%$ were used in the comparative study A, while the comparative studies B and C used slightly higher additive contents (2, 4 and 6\%) because they are comparing different grade bitumens. The modified binders were obtained by mixing the bitumen with the additive for a period of five minutes at a temperature of $130^{\circ} \mathrm{C}$.

In order to classify the binders used in this study, a basic characterization was performed as referred in section 3.1.2. The results obtained for the paving grade bitumens and for those obtained by the addition of a certain amount of additive are summarized in Figure 5 .

In the first comparative study (binder A1 vs. A2) the addition of increasing quantities of wax additive to the B50/70 bitumen significantly modifies its properties, mainly the softening point temperature. The modified binder A2 can be classified as a harder binder type (like a B35/50), with a penetration grade clearly different from binder A1 (independently of using 2, 3 or $4 \%$ of additive). Thus, the selection of the optimum additive content in this study was based on the viscosity results, in order to allow an adequate reduction of temperature.

The most significant changes caused by the wax additive were observed in the comparative study B, in which the synthetic wax dramatically hardens the very soft base bitumen (B160/220) used to produce the modified binder B2. Thus, a great reduction in the penetration and a huge increase in the R\&B temperature were observed just by using $2 \%$ of additive. However, it was necessary to use the highest additive content (6\%) in the modified binder B2 in order to obtain a penetration grade near that of binder B1 (B50/70), and so the optimum additive content selected to continue this comparative study was $6 \%$. This additive content was also selected since it increased the softening point temperature of the base bitumen by $50^{\circ} \mathrm{C}$ (doubling the initial value). 
Finally, when comparing binders $\mathrm{C} 1$ and $\mathrm{C} 2$, it was observed that the higher the quantity of wax additive used to modify the B35/50 bitumen, the closer the penetration grade of binder $\mathrm{C} 2$ becomes to that of binder $\mathrm{C} 1(\mathrm{~B} 10 / 20)$. However, it was not possible to obtain the same penetration of bitumen $\mathrm{B} 10 / 20$, even when using the highest additive content of $6 \%$ in the modified binder $\mathrm{C} 2$. Concerning the softening point temperature, the addition of the synthetic wax generated a significant change in the binder, thus being possible to obtain the same R\&B temperature of binder $\mathrm{C} 1$ (B10/20) by modifying the bitumen B35/50 with only $2 \%$ of additive. Considering both results, as well as the cost/benefit relationship, the optimum additive content considered as "ideal" to continue this study was $6 \%$.

\subsubsection{Dynamic viscosity and pre-selection of production temperatures}

In order to evaluate the properties of the various binders at higher temperatures (100 to $\left.170{ }^{\circ} \mathrm{C}\right)$ in which the bituminous mixtures are mixed and applied, their dynamic viscosity was accessed using a rotating spindle apparatus (as described in section 3.1.3). The evolution of the dynamic viscosity with the temperature for different types of paving grade bitumens, before and after their modification with different amounts of the WMA additive, can be observed in Figure 6 .

In general, it was observed that the decrease of the dynamic viscosity of the WMA modified binder is proportional to the used amount of synthetic wax additive. Thus, considering the main objective of WMA mixtures, i.e. reducing the mixing temperature, the maximum amount of additive should be selected to continue the three comparative studies. However, in order to maximize the temperature reduction it is more effective to use a softer base bitumen than to increase the amount of additive, as was observed by the viscosity of the final binder.

Actually, Figure $6 a$ (case study A) shows that the addition of the synthetic wax has little effect in the reduction of the dynamic viscosity of the binder at production and application temperatures, because the base bitumen used to produce the WMA modified binder will also be used as HMA binder. Thus, the changes observed at these temperatures are visibly lower than those 
observed at in service conditions (penetration and R\&B). After analysing the temperatures at the limit equal-viscosity line for mixing ( $0.3 \mathrm{~Pa} . \mathrm{s})$, it can be concluded that the addition of $2 \%$ of additive only allows reducing $3{ }^{\circ} \mathrm{C}$ in comparison with the neat bitumen (A1), while the binder modified with $4 \%$ of additive (modified binder A2 selected in case study A) presented a slightly higher reduction $\left(9^{\circ} \mathrm{C}\right)$.

In contrast, Figures $6 \mathrm{~b}$ (case study B) and $6 \mathrm{c}$ (case study $\mathrm{C}$ ) show that the addition of the synthetic waxes to softer base bitumens (in comparison to the bitumen used in the HMA mixture) is obviously the best solution to reduce the dynamic viscosity of the WMA binder at production and application temperatures (and consequently the mixing temperature). When comparing the temperatures at the limit equal-viscosity line for mixing (0.3 Pa.s), it was observed that:

- the addition of $2 \%$ of wax to the $\mathrm{B} 160 / 200$ bitumen allows reducing $19{ }^{\circ} \mathrm{C}$ in comparison with the neat bitumen B50/70 (B1), while the binder B160/200 modified with $6 \%$ of additive presented a higher reduction $\left(27^{\circ} \mathrm{C}\right)$, thus being selected as the modified binder B2 (Figure 6b);

- the addition of $2 \%$ of wax to the B35/50 bitumen allows reducing $27^{\circ} \mathrm{C}$ in comparison with the neat bitumen $\mathrm{B} 10 / 20(\mathrm{C} 1)$, but the maximum reduction of temperature $\left(36^{\circ} \mathrm{C}\right)$ was obtained with the binder B35/50 modified with $6 \%$ of wax (selected as the modified binder C2 - Figure 6c).

Following the characterisation of the different binders, the study of the WMA mixtures was carried out using the neat bitumens (A1, B1 and C1) and modified binders (A2, B2, C2) presented in Figure $6 \mathrm{~d}$. The pre-selection of the mixing temperatures for the HMA and WMA mixtures was based on the evaluation of the viscosity results presented in this Figure. However, the mixing and application of bituminous mixtures do not depend merely on the viscosity of the binder, and additional compactability tests were carried out to select the mixing temperature.

\section{Study of the Mixture Production Method}




\subsection{Aggregate gradation}

Three different mixtures were used in the present study, in order to carry out the three different comparative studies (HMA vs. WMA) previously stated. Two of them (Mix A and Mix B) should be used in a surface course layer and, therefore, should comply with the grading requirements for that type of mixture. The third mixture (Mix C) is a high stiffness modulus mixture, which should be used in a base course, and its grading envelope is different from the previous, according to the material specifications. The grading curves of the three studied mixtures can be observed in Figure 7.

Mixture A was used in a real pavement trial and its aggregate was imposed by local conditions (mostly related to material availability). Thus, it is different (in type and gradation) from the aggregate used in the other mixtures, as can be observed in Figure 7.

\subsection{Mixture design}

The mix design of the HMA mixtures was carried out according to the Marshall Method and then, for the "equivalent" WMA mixtures, the same binder content, aggregate type and gradation was used in order to assess the influence of the binder type. It should be noted that the binder content of WMAs includes the additive, i.e. the WMA binders have less bitumen than those of the HMAs. The variables considered in the mix design of the three mixtures can be observed in Table 2.

\subsection{Validation of production temperatures}

After carrying out all the tests needed to determine the amount of additive in each mixture, the study proceeded with the validation of the production and compaction temperatures. This was done according to the EN 12697-10 standard, using the impact compactor (same as used in the 
Marshall method) and monitoring the thickness of each specimen during the compaction operation, by recording the corresponding number of blows.

For each type of mixture (A, B and C), the test was first carried out for the HMAs and subsequently for the WMAs. The temperature used for the HMAs was defined by EN 12697-35 and for the WMAs three different temperatures were used in order to determine the one that would result in an air voids content of the mixture closest to that of the HMA. For each set of mixture/temperature three specimens were produced and the average was calculated to account for some common variability. The results obtained for the three mixtures under study are presented in Figure 8.

Based on the results presented in Figure 8, it was possible to confirm that, for the first study (Mixture A), the production/compaction temperature could be reduced by $15^{\circ} \mathrm{C}$ for the WMA (produced at $135^{\circ} \mathrm{C}$ ) without compromising the target air voids content of the mixture. For the other two mixtures it was possible to obtain a more significant reduction on the temperature due to the use of softer bitumens. Thus, it was possible to reduce the production temperature by $30^{\circ} \mathrm{C}$ for Mixture $\mathrm{B}$ (produced at $120^{\circ} \mathrm{C}$ ), which is even higher than the expected reduction $\left(25^{\circ} \mathrm{C}\right.$, according to Figure 6), and by $40^{\circ} \mathrm{C}$ for Mixture $\mathrm{C}$ (produced at $140^{\circ} \mathrm{C}$ ). These temperatures could even be further reduced $\left(110^{\circ} \mathrm{C}\right.$ for mixture $\mathrm{B}$ and $130^{\circ} \mathrm{C}$ for mixture $\left.\mathrm{C}\right)$ taking into account the target air voids content and the compactability test results obtained within laboratory controlled conditions. However, taking into consideration the viscosity results and the congealing temperature of the synthetic wax (above $100^{\circ} \mathrm{C}$ ), it was decided to keep these more conservative values (in order to account for eventual difficulties in controlling the field conditions).

In order to assess if the performance of the WMA mixtures was comparable/equivalent to that of the HMAs, several complementary tests were carried out, as presented in Section 5. 
Additionally, the compaction resistance was calculated according to the procedure described in EN 12697-10 (Equation 1) and presented in Table 3.

$$
\frac{1}{t\left(E_{2}\right)}=\frac{1}{t_{\infty}}-\left[\frac{1}{t_{\infty}}-\frac{1}{t_{0}}\right] \exp \left(\frac{-E_{2}}{T}\right)
$$

Where:

$t\left(E_{2}\right)$ is the thickness of the specimen at a compaction energy $E_{2}$ using an impact compactor $(\mathrm{mm})$;

$t_{\infty} \quad$ is the calculated minimum achievable specimen thickness by impact compaction $(\mathrm{mm})$;

$t_{0} \quad$ is the calculated initial specimen thickness by impact compaction $(\mathrm{mm})$;

$E_{2}$ is the compaction energy (impact compactor), expressed with $21 \mathrm{Nm}$ as unit, its numerical value is equal to the number of blows to the specimen;

$T \quad$ is the compaction resistance (impact compaction, method with the same specimen for all levels of compaction energy), expressed with $21 \mathrm{Nm}$ as unit.

According to the results presented in Figure 8 and Table 3 it is possible to conclude that the air voids content obtained for 150 blows (compaction energy specified in Portugal) on the impact compactor are close to the target and within the specified values (3 to $5 \%$ for Mixtures A and B and 2 to $6 \%$ for Mixture $\mathrm{C}$ ). It is also possible to confirm that the results obtained (for both compaction resistance and air voids content) for the WMA mixtures, produced at the chosen temperatures (mentioned above), are in accordance with those obtained for the HMAs.

\section{Performance of the mixtures}

5.1. Laboratory programme

After determining the amount of additive and the mixing temperatures for the WMA mixtures, and based on the mix design carried out for the HMA mixtures, the engineering properties of the 
final WMA mixtures were assessed through laboratory testing in order to determine relative measures of performance in comparison with the corresponding HMA mixtures.

Initially, the studied mixtures were produced in a laboratory mixer, being then compacted into slabs with a roller compactor. The slabs were then cut into prismatic and cylindrical specimens with dimensions specified in the European standards for every test to be carried out. The volumetric characteristics of the specimens were measured to validate the lower mixing temperatures of the WMA mixtures and to obtain additional information for the analysis of the test results. Finally, the performance of the various WMA and HMA mixtures was evaluated and compared regarding their water sensitivity, resistance to permanent deformation, stiffness moduli and fatigue resistance.

\subsection{Volumetric characteristics}

In order to confirm the volumetric properties of each mixture, the air voids content and the binder content were determined for all specimens used in each type of test (ITSR, WTT and Stiffness/Fatigue) according to EN 12697-8 and EN 12697-39, respectively, as can be observed in Table 4.

The results presented in Table 4 show that, in most cases, the use of the additive slightly reduced the air voids content (when comparing the WMA with the HMA mixture) without compromising the target values. Regarding the bitumen content, it can be observed that the values obtained are generally very close to the target (5.0\% for mixtures $A$ and $B$ and $5.3 \%$ for mixture $\mathrm{C}$ ). The variability observed is within an acceptable range but may explain some results obtained, as presented in the following sections, e.g., the slightly higher bitumen content obtained for mixture $\mathrm{C} 2$ (in comparison the mixture $\mathrm{C} 1$ ) can partially justify the lower stiffness modulus obtained.

\subsection{Water sensitivity}


The influence of water in the reduction of the performance of WMA mixtures has been reported as one of the issues that need to be carefully controlled. Thus, in the present study, all mixtures were tested for water sensitivity according to the EN 12697-12 standard. This test comprises the assessment of the indirect tensile strength (ITS), carried out according to EN 12697-23, of two identical groups of specimens conditioned in different environments (dry and wet with the application of vacuum). The test procedure includes also the evaluation of the ratio (ITSR) between the average strength results of both groups of specimens (wet over dry), in order to assess the water sensitivity of the mixture. The results obtained for the mixtures under study can be observed in Figure 9.

Figure 9 shows that the use of the 4\% of additive slightly decreased the ITSR of mixture A, while the ITS has slightly increased due to the stiffening effect of the wax. Although the difference is not significant, it confirms the tendency of the wax additives to increase the water sensitivity of bituminous mixtures. However, if a softer base bitumen is used in the modified binder, the same does not occur, due to the better adhesion between aggregates and binder provided by the softer bitumen (as can be observed for mixtures B and C). The ITSR results of each type of mixture presented in Figure 9 were also affected by the type of aggregate. In this particular study, the aggregates used in mixture A (syenites) have significantly influenced the results obtained for the ITSR of that mixture (with the ratio of both HMA and WMA mixtures below 50\%). One of the reasons for the higher results obtained for mixture C (if compared to mixture B) is probably related to the higher binder content of the specimens as previously presented.

\subsection{Resistance to permanent deformation}

In this study, the determination of the resistance to permanent deformation was carried out using the Wheel-Tracking Test, WTT (according to EN 12697-22 standard). The susceptibility of the WMA and HMA mixtures to deform was assessed by measuring the rut depth formed by 
repeated passes of a loaded wheel at a temperature of $50^{\circ} \mathrm{C}$ (maximum temperature typically observed during summer in several regions of Portugal). The evolution of the rut depth $(\mathrm{mm})$ in air of the studied mixtures with the number of load cycles at $50^{\circ} \mathrm{C}$ is presented in Figure 10.

The average results of the wheel-tracking tests required by the EN 12697-22 standard to rank the performance of the studied mixtures are the Mean wheel-tracking slope $\left(\mathrm{WTS}_{\mathrm{AIR}}\right)$, Mean proportional rut depth $\left(P R D_{A I R}\right)$ and Mean rut depth $\left(R D_{A I R}\right)$, in air, which are shown in Table 5.

One of the main advantages of the introduction of wax additives in bituminous mixtures is the reduction of their permanent deformation susceptibility. This is clear in the results presented in Figure 10 and Table 5, where the performance of mixture $A 2$ is better than that of mixture A1 (using the same base bitumen). The effect of the additive on the performance of mixture A2 should be highlighted, as the wheel-tracking slope has been reduced to less than half, when compared to mixture A1. As for mixtures B1 and B2, the results are very close to each other even though the base bitumen used in mixture B2 is significantly softer than that of mixture B1, which confirms the role of the wax additive. For mixtures B2 and C2, after an increased rate of deformation observed at the beginning of the test (and the corresponding mean rut depth), the wheel-tracking slope calculated between the $5000^{\text {th }}$ and the $10000^{\text {th }}$ cycle shows equivalent values. Thus, it can be stated that the objective of obtaining comparable HMA and WMA mixtures (in case studies B and C), in terms of resistance to permanent deformation was fulfilled, as the results of the wheel-tracking tests are approximately the same.

\subsection{Stiffness Modulus}

The structural performance of the pavements is directly related to the mechanical behaviour of the bituminous mixtures, which can be characterised through the stiffness modulus and phase angle. In this work, these properties were obtained for the WMA and HMA mixtures by using the four-point bending beam test, with a repetitive sinusoidal loading configuration, as stated in the EN 12697-26 standard. The frequency sweep $(0.1$ to $10 \mathrm{~Hz})$ tests were carried out at $20^{\circ} \mathrm{C}$. The 
variation of the stiffness modulus and phase angle of the studied mixtures with the frequency, at the reference temperature of $20^{\circ} \mathrm{C}$, is presented in Figure 11.

According to the results presented in Figure 11, it can be concluded that the additive has a stiffening effect on the binder and consequently on the mixtures (as confirmed by the higher stiffness values obtained for mixture A2 at the different frequencies in comparison to mixture A1). However, when softer binders are used, the effect of the additive is not so significant (the stiffness moduli of mixtures B2 and C2 were lower than those of mixtures B1 and C1, respectively). Nevertheless, it can be observed that the mixtures incorporating modified binders (WMAs) have shown a more elastic behaviour, as the phase angle of such mixtures is less susceptible to the test frequencies and shows lower values for the lower frequencies than those of the HMAs.

\subsection{Resistance to Fatigue}

The fatigue cracking resistance of bituminous mixtures represents their ability to resist to the application of repetitive bending loads before failure. In this work, the fatigue cracking resistance of the mixtures was obtained through four-point bending tests (EN 12697-24 standard), carried out in strain control mode and with a repetitive sinusoidal loading configuration without rest periods. These tests were carried out at $20^{\circ} \mathrm{C}$, at a frequency of 10 $\mathrm{Hz}$ and at three different tensile strain levels, with three specimens tested for each strain level. The initial stiffness modulus of each tested specimen and the number of cycles that correspond to a $50 \%$ reduction of its initial value (failure criterion) was registered, thus obtaining the fatigue life of the specimen. With these results, it was possible to determine the fatigue lines of the different WMA and HMA mixtures under study, which are presented in Figure 12.

The fatigue cracking resistance of mixtures B2, C1 and C2 is visibly higher (10 times superior) than that of the other mixtures. The main reasons to justify these results are the use of a very 
soft bitumen to produce the WMA mixture B2 and the specific mix design of mixtures $\mathrm{C} 1$ and C2, which have a higher binder content.

The comparative performance of WMA and HMA mixtures showed that, in case studies A and $\mathrm{C}$, the fatigue resistance of the synthetic wax modified mixtures (A2 and C2) is similar to that of the HMA mixtures ( $\mathrm{A} 1$ and $\mathrm{C} 1$, respectively), even if a slight decrease in the fatigue resistance of the WMAs was noticed. In case study B, the WMA mixture (B2) was clearly less susceptible to fatigue cracking than the HMA mixture (B1), due to the use of a very soft base bitumen (B160/220) and the lower effect of ageing in the WMA mixture [17], produced at lower temperatures.

The intrinsic effect of the synthetic wax additive is detrimental for the fatigue cracking resistance, because the wax is very rigid and brittle at service temperatures. This can be observed essentially in the fatigue slope, where the WMA mixtures become more susceptible to changes in the strain level than the HMA mixtures (mixture $C$ is an exception that may be explained by the higher binder content). However, the following phenomena, which are beneficial for the fatigue resistance, occur at the same time when WMA mixtures are produced with this additive:

- WMAs are produced at lower temperatures, reducing the ageing of the binder and increasing the flexibility of the mixtures;

- It is possible to use softer base bitumens without compromising the rutting resistance, thus increasing the flexibility of the mixtures and, hence, their fatigue cracking resistance.

\section{Summary and conclusions}

In order to optimize the use of synthetic wax additives in warm mix asphalts, different blends of penetration grade bitumens and additive contents were prepared and characterised through penetration, softening point, viscosity and rheology tests. Three comparative studies between HMA and WMA mixtures emerged from the analysis of the binder properties, after carefully 
selecting the optimum amount of additive and the production temperature of every mixture. For each comparative study, the relative measures of performance (water sensitivity, stiffness, resistance to fatigue and permanent deformation) between the WMA and HMA mixtures are summarised in Table 6, in order to ease the evaluation of the main advantages and weaknesses of the different solutions.

The main conclusion of this work is related with the possibility of designing the WMA mixture, using specific combinations of penetration grade bitumens and synthetic wax additives, in order to optimize the performance of the mixture for one particular property, according to in situ conditions, without compromising the other properties. Thus, the best WMA solution for hot climates is the one presented in case study A (higher increase in the permanent deformation resistance), while the best solution for cold/warm climates is the one presented in case study $B$ (higher increase in the fatigue resistance). The higher reduction of temperature was obtained in case study C, being a good alternative to produce high modulus WMAs.

Based on the results presented in this paper and on their analysis, the following conclusions can also be drawn from this study:

- the best solution for the production of WMA mixtures with the incorporation of synthetic wax additives is by using softer base bitumens, in order to maximise the reduction of the mixing temperatures, except for very hot climates;

- this particular additive significantly changes the properties of the binder at higher service temperatures (increasing the permanent deformation resistance), while the reduction of the viscosity at production temperatures is not so evident;

- the compactability of the WMAs studied is similar or even better than that of the corresponding HMA mixtures;

- the addition of synthetic waxes does not significantly change the water sensitivity of the studied WMA mixtures; 
- the use of this additive increases the stiffness moduli and the rut resistance of the WMA in comparison with the HMA mixture produced with the same bitumen, allowing the use of a softer bitumen to obtain a WMA mixture with a similar performance;

- the fatigue resistance of the studied mixtures can only be improved by using softer binders, due to the brittle behaviour of the additive.

\section{Acknowledgments}

The authors would like to thank the MSc students and the technicians from the University of Minho and from Gabriel Couto SA for their essential support in the development of this research work, and Galp, Cepsa and Sasol (trough its representative Iberceras) for supplying the binders and the synthetic wax additive.

\section{References}

[1] Olard F, Noan C. Low Energy Asphalts. Routes Roads 336/337, PIARC, 2008. pp 131-145. [2] Hurley GC, Prowell BD. Evaluation of Potential Processes for Use in Warm Mix Asphalt. Journal of the Association of Asphalt Paving Technologists, 2006. Vol. 75, pp 41-90.

[3] EAPA. Environmental Guidelines on Best Available Techniques (BAT) for the Production of Asphalt Paving Mixes. European Asphalt Pavement Association, Brussels, 2007. [4] EAPA. Developments in Low Temperature Asphalt - EAPA Position Paper. European Asphalt Pavement Association, Brussels, 2005.

[5] Fitts G. Warm Mix Asphalt: Experience in Texas. 32nd Annual Asphalt Conference, Asphalt Institute, 2008. <http://www.acaf.org/2008\%20Conference/WarmMixInTexas-Fitts.pdf> (accessed on 11Aug09).

[6] van de Ven MFC, Jenkins KJ, Voskuilen JLM, van den Beemt R. Development of (half) warm foamed bitumen mixes: state of the art. Int. Journal of Pavement Eng., 2007; 8(2): 163-175. [7] KJ. Jenkins, Mix Design Considerations for Cold and Half-Warm Bituminous Mixes with Emphasis on Foamed Bitumen. Ph.D. Thesis, University of Stellenbosch, South Africa, 2000. 
[8] Prowell BD, Hurley GC, Crews E. Field Performance of Warm Mix Asphalt at the NCAT Test Track. TRR 1998, Transportation Research Board, Washington, D.C., 2007, pp 96-102.

[9] Hurley G, Prowell B. Evaluation of Evotherm ${ }^{\circledR}$ for Use in Warm Asphalt Mixes. NCAT Report No. 06-02, Auburn University, Auburn, 2006.

[10] Hurley GC, Prowell BD. Evaluation of Aspha-Min® Zeolite for Use in Warm Mix Asphalt. NCAT Report 05-04, Auburn University, Auburn, 2005.

[11] Hurley GC, Prowell BD. Evaluation of Sasobit ${ }^{\circledR}$ for use in Warm Mix Asphalt. NCAT Report 05-06, Auburn University, Auburn, 2005.

[12] Button JW, Estakhri C, Wimsatt A. A Synthesis of Warm-Mix Asphalt. Report 0-5597-1, Texas Transportation Institute, Texas, 2007.

[13] Sasol Wax GmbH. The Bitumen Additive for Highly Stable Easily Compactible Asphalts. Sasobit ${ }$ Product Information 124, Sasol Wax GmbH, Hamburg, 2004.

[14] CECA. Green Road Formulation - Warm Mix Asphalt - Cecabase RT. Ceca, Arkema Group, 2008, <http://www.cecachemicals.com/sites/ceca/en/business/bitumen_additive s/warm_coated_material/warm_coated_material.page> (accessed on 4Nov08).

[15] Asphalt Pavement Association of Oregon. Warm Mix Asphalt Shows Promise for Cost Reduction, Environmental Benefit, Centerline. Asphalt Pavement Association of Oregon, 2003. [16] Stroup-Gardiner M, Lange C. Characterization of Asphalt Odors and Emissions. In: Proc. of the Ninth International Conference on Asphalt Pavements. Copenhagen, Denmark, 2002. [17] D’Angelo J, Harm E, Bartoszek J, Baumgardner G, Corrigan M, Cowsert J, Harman T, Jamshidi M, Jones W, Newcomb D, Prowell B, Sines R, Yeaton B. Warm-Mix Asphalt: European Practice. FHWA, AASHTO, NCHRP, Report no. FHWA PL-08-007, Alexandria, 2008. [18] Park K, Hwang Y, Seo S, Seo H. Quantitative Assessment of Environmental Impacts on the Life Cycle of Highways. Journal of Construction Engineering and Management, American Society of Civil Engineers, 2003; 129(1): 25-31.

[19] Soenen H, Tanghe T, Redelius P, de Visscher J, Vervaecke F, Vanelstraete A. A Laboratory Study on the Use of Waxes to Reduce Paving Temperatures. In: 4th Eurasphalt \& Eurobitume Congress, Copenhagen, 2008. 
[20] Hurley GC, Prowell BD. Field Performance of Warm Mix Asphalt. TRB 2008 Annual Meeting, Washington D.C., 2008.

[21] Su K, Maekawa R, Hachiya Y. Laboratory evaluation of WMA mixture for use in airport pavement rehabilitation. Construction and Building Materials, 2009; 23(7):2709-2714. doi:10.1016/j.conbuildmat.2008.12.011.

[22] Newcomb D. An Introduction to Warm-mix Asphalt. National Asphalt Pavement Association, 2006.

[23] Sasol. Sasobit Technology. Sasol Wax, 2008.

<http://www.sasolwax.com/Sasobit_Technology.html> (Accessed on 4Nov08).

[24] Asphalt Institute. Superpave Performance Graded Asphalt Binder Specification and Testing, Superpave Series No. 1 (SP-1), Lexington, Kentucky, 1997. 


\section{Table Captions}

Table 1. Comparative studies between HMAs and WMAs carried out in this work

Table 2. Variables considered in the different mixtures studied

Table 3. Compaction resistance (EN 12697-10) obtained at different mixing temperatures

Table 4. Volumetric characterisation of the studied mixtures

Table 5. Permanent deformation parameters obtained according to EN 12697-22 standard

Table 6. Summary of the results of the three comparative studies between HMAs and WMAs 


\section{Figure Captions}

Figure 1. Classification of WMA technology based on the reduction of mixing temperature [1]

Figure 2. Method used to assess the viscosity at different temperatures in a rotating spindle apparatus

Figure 3. Influence of the additive content in the complex modulus of the binder (DSR)

Figure 4. Complex modulus of B35/50 bitumen vs. B50/70 synthetic wax modified binder (DSR)

Figure 5. Evolution of the penetration and ring \& ball values with the amount of additive

Figure 6. Evolution of the dynamic viscosity at mixing/application temperatures with the amount of additive

Figure 7. Grading curves of the aggregates used in the studied mixtures

Figure 8. Evolution of the air voids content with the compaction energy at different mixing temperatures

Figure 9. Water sensitivity results of the studied mixtures

Figure 10. Evolution of the permanent deformation of the studied mixtures in the WTT

Figure 11. Stiffness modulus and phase angle results of the studied mixtures

Figure 12. Four point bending fatigue test results of the studied mixtures 
Table 1. Comparative studies between HMAs and WMAs carried out in this work

\begin{tabular}{|c|c|c|c|c|c|}
\hline $\begin{array}{l}\text { Comparative } \\
\text { study }\end{array}$ & $\begin{array}{l}\text { Bitumens used in HMA } \\
\text { and WMA }\end{array}$ & Gradation & Mixtures & $\begin{array}{l}\text { Technology of } \\
\text { production }\end{array}$ & Binder \\
\hline \multirow{2}{*}{ A } & \multirow{2}{*}{ Same } & \multirow{2}{*}{ AC 14 Surf } & A1 & HMA & $\mathrm{B} 50 / 70$ \\
\hline & & & $\mathrm{A} 2$ & WMA & B50/70+Additive \\
\hline \multirow{2}{*}{ B } & \multirow{2}{*}{$\begin{array}{l}\text { Different } \\
\text { (soft bitumens) }\end{array}$} & \multirow{2}{*}{ AC 14 Surf } & B1 & HMA & $\mathrm{B} 50 / 70$ \\
\hline & & & B2 & WMA & B160/220+Additive \\
\hline \multirow{2}{*}{ C } & \multirow{2}{*}{$\begin{array}{l}\text { Different } \\
\text { (hard bitumens) }\end{array}$} & \multirow{2}{*}{ AC 20 Base } & C1 & HMA & $\mathrm{B} 10 / 20$ \\
\hline & & & $\mathrm{C} 2$ & WMA & B35/50+ Additive \\
\hline
\end{tabular}


Table 2. Variables considered in the different mixtures studied

\begin{tabular}{lllll}
\hline Mixture & Reference & Binder type & Binder content (\%) & Aggregate type \\
\hline A & A1 & B50/70 & 5.0 & Syenite \\
& A2 & B50/70 + 4\% additive & 5.0 & \\
B & B1 & B50/70 & 5.0 & Granite \\
& B2 & B160/220 + 6\% additive & 5.0 & \\
C & C1 & B10/20 & 5.3 & Granite \\
& C2 & B35/50 +6\% additive & 5.3 & \\
\hline
\end{tabular}


Table 3. Compaction resistance (EN 12697-10) obtained at different mixing temperatures

\begin{tabular}{lcccccccccccc}
\hline Mixture & $\mathrm{A} 1$ & & $\mathrm{~A} 2$ & & $\mathrm{~B} 1$ & & $\mathrm{~B} 2$ & & $\mathrm{C} 1$ & & $\mathrm{C} 2$ & \\
Temperature $\left({ }^{\circ} \mathrm{C}\right)$ & 150 & 140 & 130 & 120 & 150 & 130 & 120 & 110 & 180 & 150 & 140 & 130 \\
\hline $\begin{array}{l}\text { Air voids after 150 } \\
\text { blows (\%) }\end{array}$ & 4.4 & 4.2 & 4.5 & 5.1 & 3.9 & 2.3 & 3.5 & 4.1 & 3.3 & 2.9 & 3.7 & 3.9 \\
$\begin{array}{l}\text { Compaction } \\
\text { resistance T (21 Nm) }\end{array}$ & 33.9 & 31.2 & 31.8 & 33.5 & 29.2 & 28.8 & 29.4 & 30.3 & 26.8 & 25.6 & 27.4 & 27.6 \\
$\begin{array}{l}\text { Minimum thickness to } \\
(\mathrm{mm})\end{array}$ & 64.2 & 63.6 & 64.3 & 64.4 & 62.7 & 61.7 & 62.3 & 62.4 & 62.1 & 62.6 & 63.0 & 63.3 \\
$\begin{array}{l}\text { Initial thickness to } \\
(\mathrm{mm})\end{array}$ & 81.6 & 82.4 & 83.2 & 82.3 & 80.4 & 79.5 & 79.4 & 80.8 & 79.0 & 78.8 & 79.9 & 81.4 \\
\hline
\end{tabular}


Table 4. Volumetric characterisation of the studied mixtures

\begin{tabular}{cccccccc}
\hline Mixture & $\begin{array}{c}\text { Temperature } \\
\left({ }^{\circ} \mathrm{C}\right)\end{array}$ & ITSR & WTT & $\begin{array}{c}\text { Air voids (\%) } \\
\text { Fatigue }\end{array}$ & ITSR & WTT & $\begin{array}{c}\text { Stiffness } \\
\text { Fatigue }\end{array}$ \\
\hline A1 & 150 & 4.03 & 4.36 & 3.98 & 4.98 & 5.03 & 5.03 \\
A2 & 135 & 4.08 & 3.97 & 4.04 & 5.00 & 4.99 & 4.98 \\
B1 & 150 & 3.58 & 3.93 & 3.64 & 5.04 & 5.03 & 5.00 \\
B2 & 120 & 3.32 & 3.76 & 3.47 & 5.06 & 5.07 & 5.10 \\
C1 & 180 & 3.77 & 3.68 & 3.68 & 5.32 & 5.21 & 5.14 \\
C2 & 140 & 3.13 & 3.84 & 3.33 & 5.35 & 5.31 & 5.39 \\
\hline
\end{tabular}


Table 5. Permanent deformation parameters obtained according to EN 12697-22 standard

\begin{tabular}{lcccccc}
\hline Mixture & A1 & A2 & B1 & B2 & C1 & C2 \\
\hline WTS $_{\text {AIR }}\left(\mathrm{mm} / 10^{3}\right.$ cycles $)$ & 0.39 & 0.16 & 0.24 & 0.25 & 0.07 & 0.06 \\
PRD $_{\text {AIR }}(\%)$ & 16.02 & 10.13 & 13.55 & 15.60 & 5.13 & 6.16 \\
RD $_{\text {AIR }}(\mathrm{mm})$ & 6.73 & 4.24 & 5.70 & 6.59 & 2.16 & 2.60 \\
\hline
\end{tabular}


Table 6. Summary of the results of the three comparative studies between HMAs and WMAs

\begin{tabular}{lcccccccccccccc}
\hline Comparative study & \multicolumn{3}{c}{ Case study A } & \multicolumn{4}{c}{ Case study B } & \multicolumn{4}{c}{ Case study C } \\
Mixture & A1 & A2 & $\Delta$ & B1 & B2 & $\Delta$ & C1 & C2 & $\Delta$ \\
\hline Temperature ( $\left.{ }^{\circ} \mathrm{C}\right)$ & 150 & 135 & -15 & $(0)$ & 150 & 120 & -30 & $(+)$ & 180 & 140 & -40 & $(++)$ \\
Amount of Additive (\%) & 0 & 4 & +4 & $(-)$ & 0 & 6 & +6 & $(-)$ & 0 & 6 & +6 & $(-)$ \\
ITSR (\%) & 47 & 42 & -5 & $(0)$ & 69 & 72 & +3 & $(0)$ & 85 & 92 & +7 & $(+)$ \\
WTS at 50 ${ }^{\circ} \mathrm{C}$ & 0.39 & 0.16 & -0.23 & $(++)$ & 0.24 & 0.25 & +0.01 & $(0)$ & 0.07 & 0.06 & -0.01 & $(0)$ \\
$\left(\mathrm{mm} / 10^{3}\right.$ cycles) & 6650 & 7450 & +800 & $(+)$ & 7200 & 4000 & -3200 & $(-)$ & 8450 & 7350 & -1100 & $(-)$ \\
Stiffness at 8Hz (MPa) & 109 & 106 & -3 & $(0)$ & 103 & 182 & +79 & $(++)$ & 187 & 176 & -7 & $(0)$ \\
Fatigue resistance $\left(\varepsilon_{6}\right)$ & 109 &
\end{tabular}




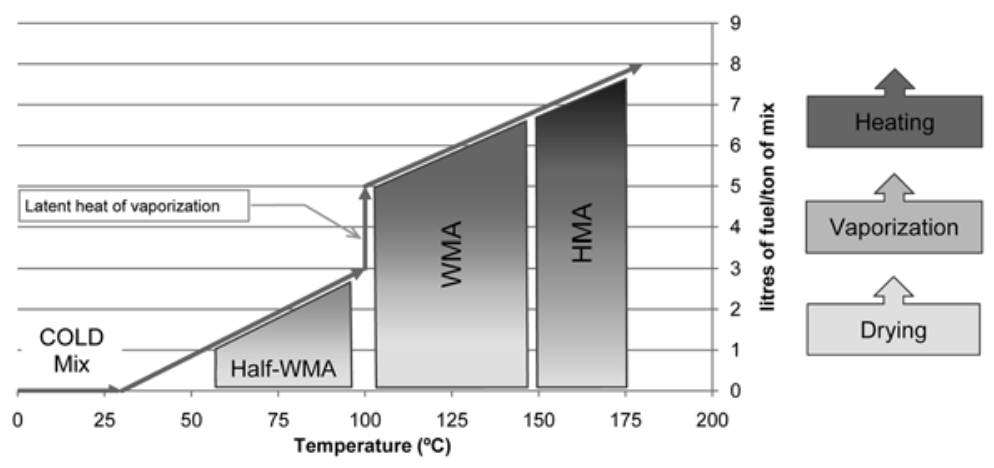

Figure 1. Classification of WMA technology based on the reduction of mixing temperature [1]

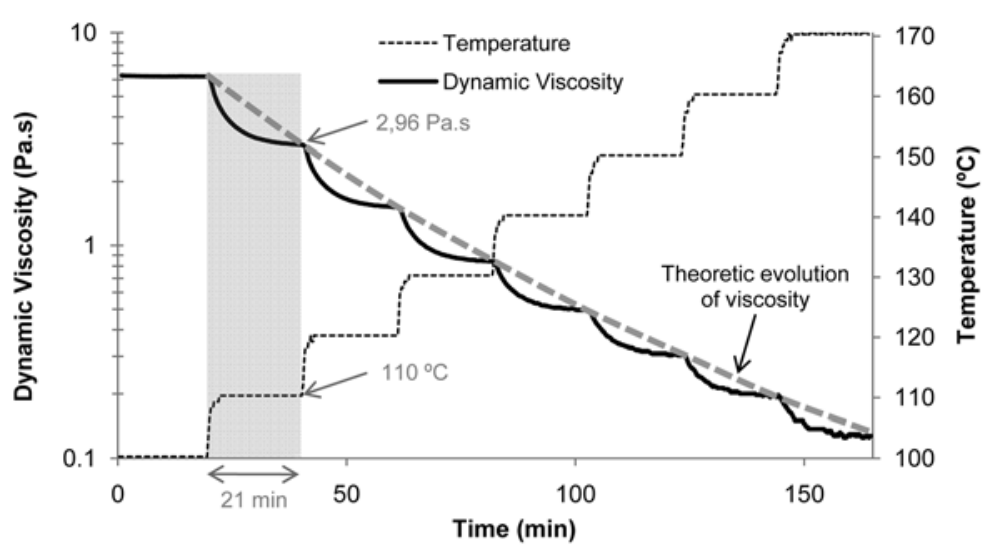

Figure 2. Method used to assess the viscosity at different temperatures in a rotating spindle apparatus

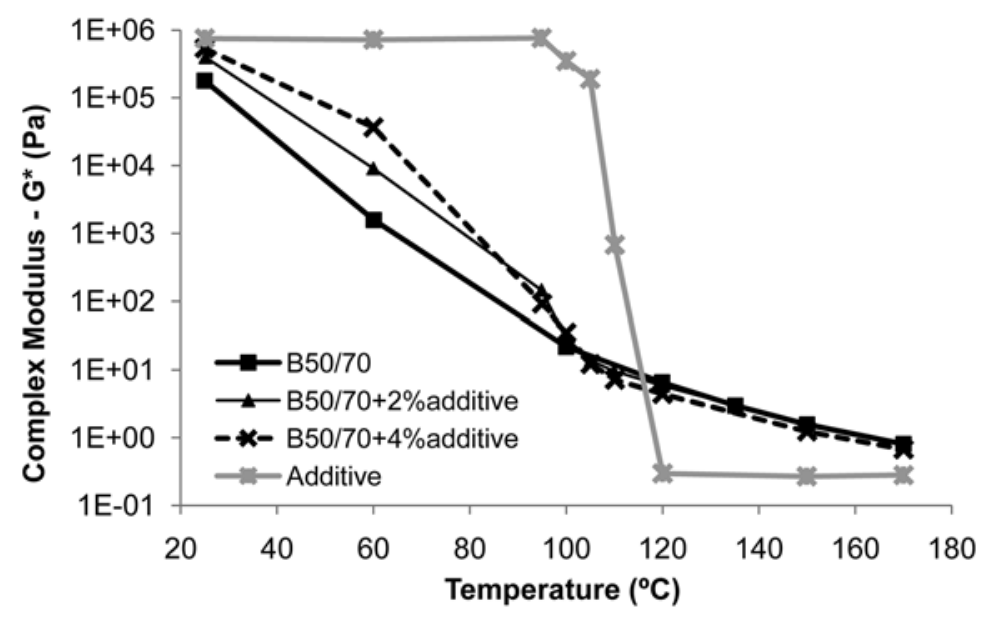

Figure 3. Influence of the additive content in the complex modulus of the binder (DSR) 


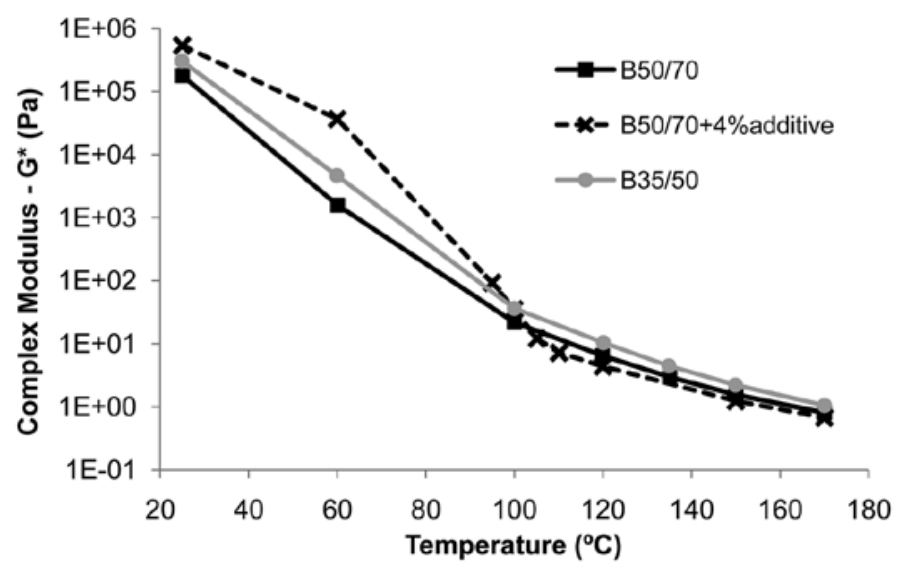

Figure 4. Complex modulus of B35/50 bitumen vs. B50/70 synthetic wax modified binder (DSR)
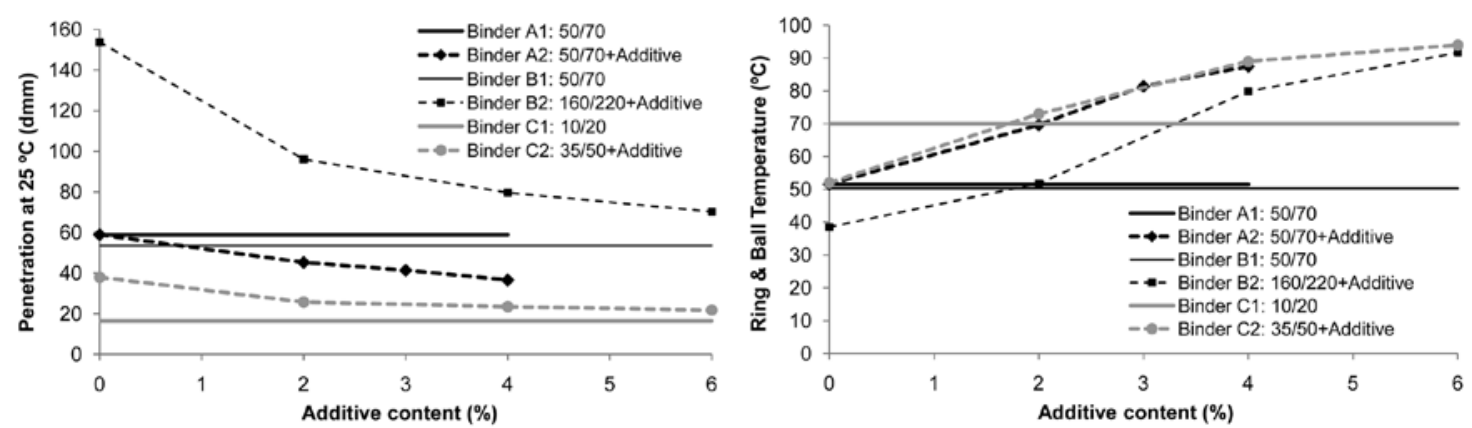

Figure 5. Evolution of the penetration and ring \& ball values with the amount of additive
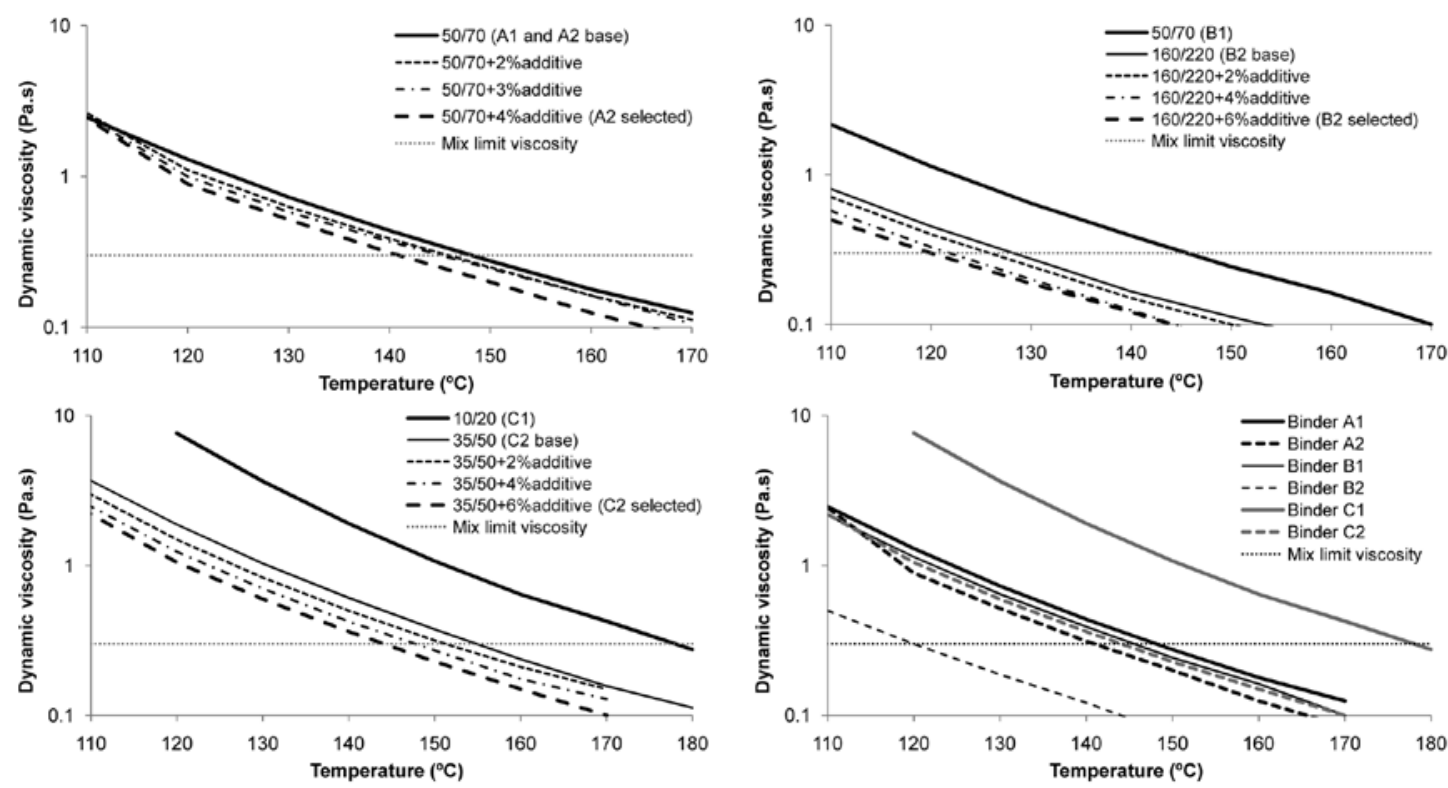

Figure 6. Evolution of the dynamic viscosity at mixing/application temperatures with the amount of additive 

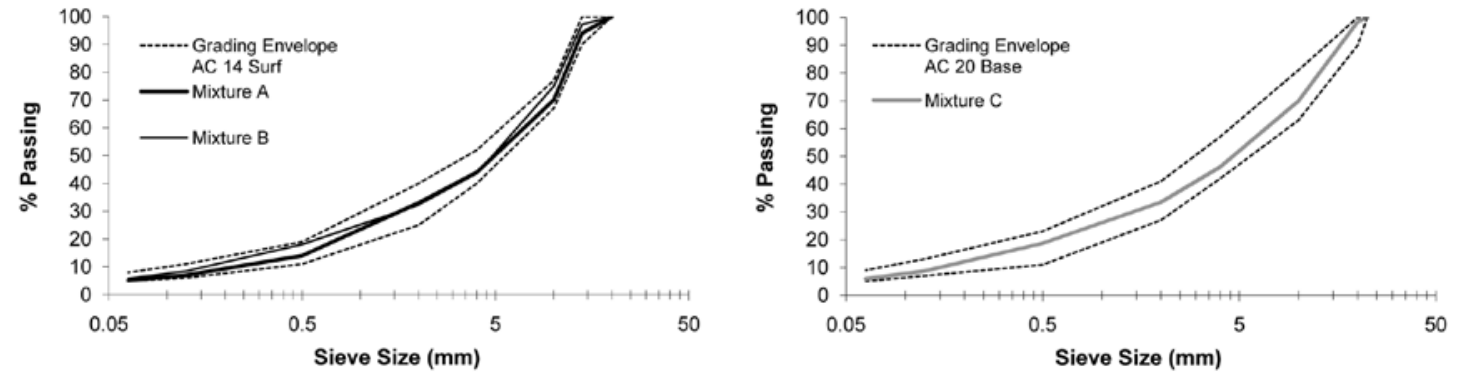

Figure 7. Grading curves of the aggregates used in the studied mixtures
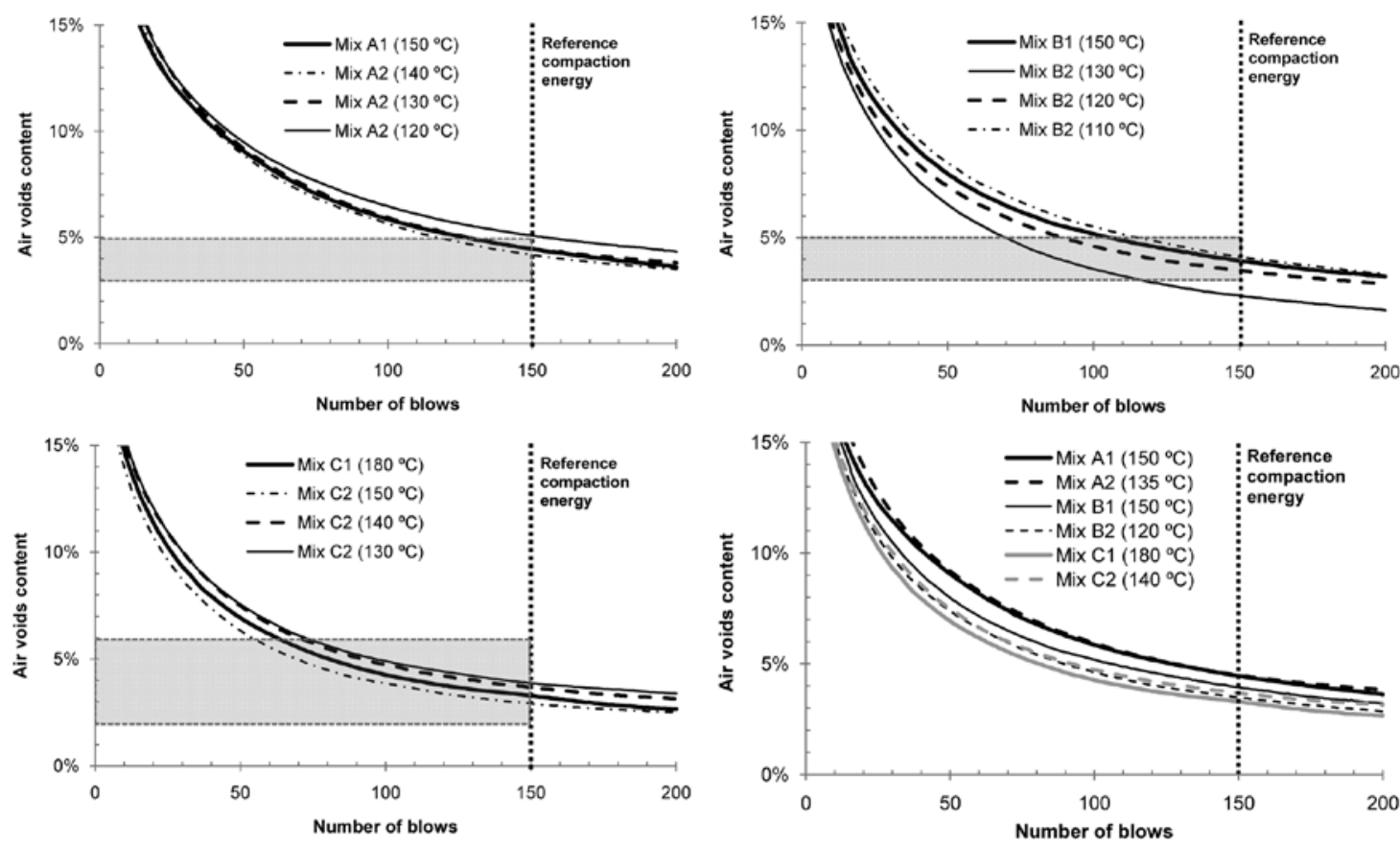

Figure 8. Evolution of the air voids content with the compaction energy at different mixing temperatures 


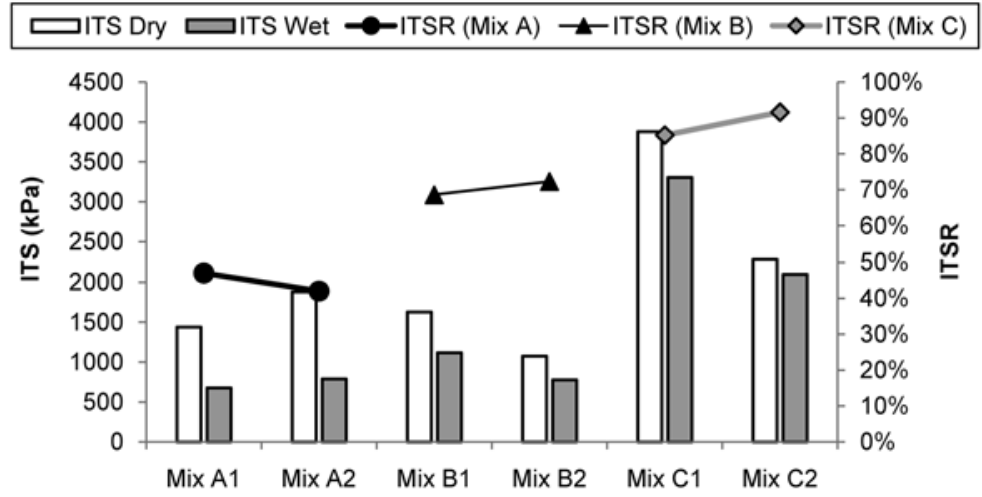

Figure 9. Water sensitivity results of the studied mixtures

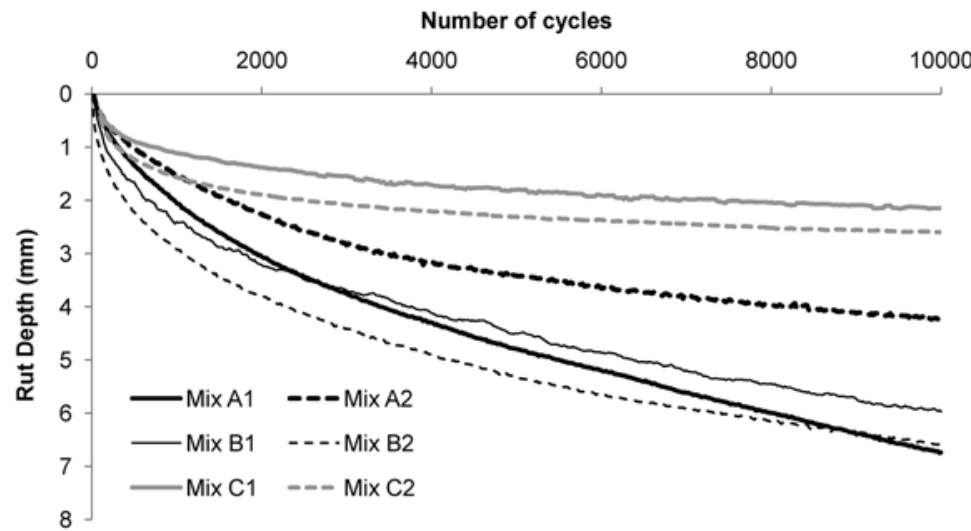

Figure 10. Evolution of the permanent deformation of the studied mixtures in the WTT
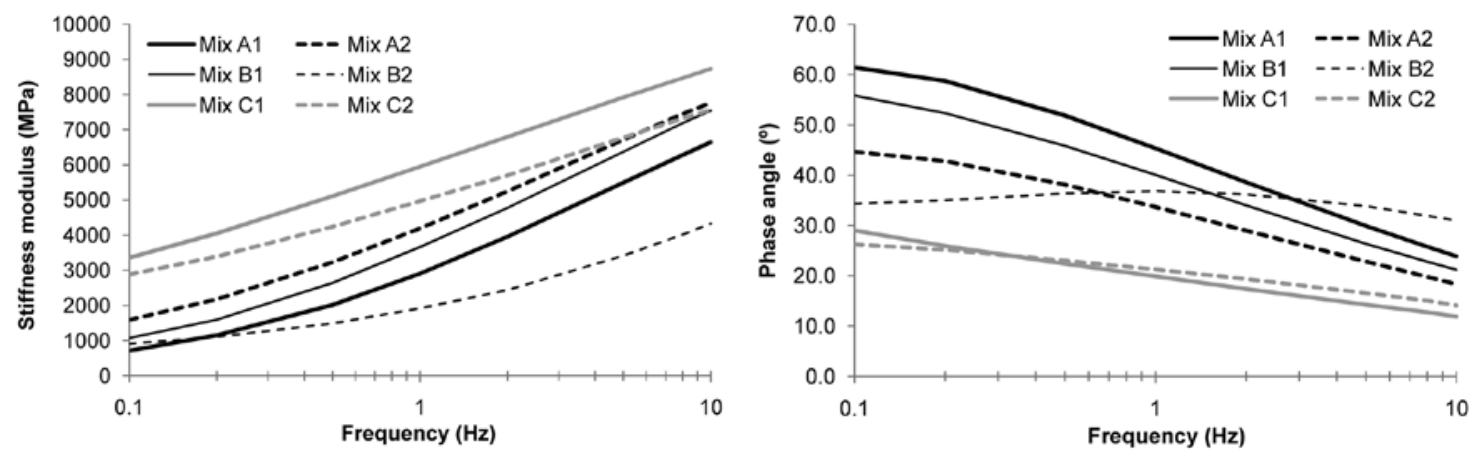

Figure 11. Stiffness modulus and phase angle results of the studied mixtures 


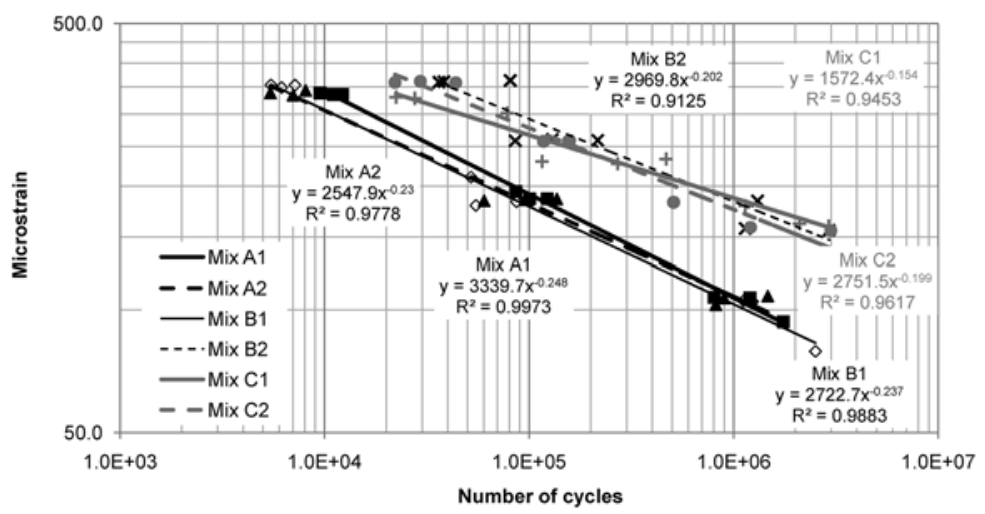

Figure 12. Four point bending fatigue test results of the studied mixtures 